\title{
Immigrant Volunteering: A Way Out of Labour Market Discrimination?*
}

\author{
Stijn Baerti, Sunčica Vujićii
}

\begin{abstract}
Many governments encourage migrants to participate in volunteer activities as a stepping stone to labour market integration. In the present study, we investigate whether this prosocial engagement lowers the hiring discrimination against them. To this end, we use unique data from a field experiment in which fictitious job applications are sent in response to real vacancies in Belgium. Ethnic origin and volunteer activities are randomly assigned to these applications. While non-volunteering native candidates receive more than twice as many job interview invitations as non-volunteering migrants, no unequal treatment is found between natives and migrants when they reveal volunteer activities.
\end{abstract}

Keywords: immigrants; volunteering; discrimination; hiring; integration.

JEL: J15; J71; D64.

\footnotetext{
*Ethical approval. The data-gathering process was reviewed and approved by the Ethical Committee of the Faculty of Economics and Business Administration of Ghent University at its meeting on 9 July 2013.

' Corresponding author. Ghent University, Research Foundation - Flanders, University of Antwerp, Université catholique de Louvain and IZA. Sint-Pietersplein 6, B-9000 Ghent, Belgium. Stijn.Baert@UGent.be. +32486492752.

ii University of Antwerp and University of Bath.
} 


\section{Introduction}

The labour market integration of migrants ${ }^{1}$ has received much attention both in policy and academic circles during the past decade. A frequently reported finding in related academic work is that immigrants' socio-cultural integration is key to their labour market success (see, e.g., Bisin et al., 2011; Constant and Zimmermann, 2008). Therefore, not surprisingly, countries such as Austria, Belgium, ${ }^{2}$ Canada, Denmark, Italy, the Netherlands and the United Kingdom have encouraged the migrants they host to participate in volunteer activities in "mainstream" organisations (European Commission, 2012; Handy and Greenspan, 2009; OECD, 2008). ${ }^{3}$ This participation in volunteer work outside their own communities not only helps migrants to catch up with natives in terms of human and social capital (European Commission, 2012) but also signals better integration to employers (Handy and Greenspan, 2009). ${ }^{4}$ As a consequence, it may lower hiring and wage discrimination. On the one hand, following Becker's (1957) model of taste-based discrimination, employers as well as their employees and customers may have less distaste for interacting with well-integrated migrants compared with their less integrated counterparts (Adida et al., 2014; Handy and Greenspan, 2009). On the other hand, following Arrow's (1973) model of statistical discrimination, the volunteering signal may weaken stereotypes with respect to foreign job candidates' productivity, values and motivation (Baert and De Pauw, 2014; Derous et al., 2009).

This study, to the best of our knowledge, is the first to assess the empirical link

\footnotetext{
${ }^{1}$ Throughout this manuscript, when referring to (im)migrants, we refer to (im)migrants in a broad sense, i.e. individuals with an (im)migration background. These can be first generation migrants (if the migration occurred during their own life), second generation migrants (if their parents migrated to Belgium before their birth) or even third generation migrants.

${ }^{2}$ In some cities in Belgium, the country where we gathered our data, for instance, language courses for migrants are made conditional on a number of hours spent volunteering (source: http://www.inburgeringantwerpen.be/participeren).

${ }^{3}$ European Commission (2012) mentions that "volunteering [...] is an essential component of what the European Commission called the Common Basic Principles of Integration."

${ }^{4}$ As mentioned by European Commission (2012), immigrant volunteering serves both as an instrument for and as an indicator of socio-cultural integration.
} 
between the volunteering undertaken by ethnic minorities and the labour market discrimination that they face. If volunteering acts as a discrimination-reducing device, this is relevant to individual migrants (when considering prosocial activities) as well as to volunteer-based organisations (when planning communication strategies to attract (immigrant) volunteers) and policy makers (when considering additional stimuli for immigrant volunteering). In addition, we investigate whether the empirical link between immigrant volunteering and discrimination is heterogeneous by gender and education level.

To this end, we analyse field experimental data gathered by correspondence testing, as introduced and refined by, amongst others, Bertrand and Mullainathan (2004), Eriksson and Rooth (2014) and Sharma et al. (2015). In the next section, we describe our research method, in which we sent fictitious job applications in response to real vacancies in Belgium and randomly assigned volunteering and ethnicity to these applications. In Section 3, we analyse the tested employers' reactions by the intersection of ethnicity and volunteering. Section 4 concludes the study.

\section{Data}

We gathered our experimental data between December 2014 and April 2015 in Flanders, the Dutch-speaking part of Belgium. We sent one pair of fictitious job applications to genuine vacancies in this region. For each vacancy, we randomly assigned volunteering activities to one of the pair members. The migrant status of the applicants was equal at the pair level, but was randomly assigned between pairs. Thereafter, reactions from the employer side were analysed to investigate the interaction of both treatments (volunteering and migrant status) on the probability of positive call-back. In what follows, we describe our experiment in more depth.

We created two templates ("Type A" and "Type B") of curricula vitae and cover letters for two education levels. Middle-educated pairs held a secondary education degree in commerce, while high-educated pairs held a bachelor's degree in office 
management. These degrees allowed us to apply for almost all commercial and administrative positions at the upper-secondary education and first-stage tertiary education levels. Type A and Type B applications differed in inessential details and in layout but were identical in all job-relevant characteristics, conditional on education level. All the applicants were born and living in Antwerp, the largest city of Flanders. Examples of the templates used are available in the Online Appendix.

We sent two applications, one of Type A and one of Type B, to each of 576 randomly selected vacancies from the database of the Public Employment Agency of Flanders: 288 vacancies targeted at our middle-educated pairs and 288 vacancies targeted at our higheducated pairs. One member of each candidate pair mentioned volunteer activities in the "Other activities" section of her/his curriculum vitae. To eliminate any applicationtype effects on call-backs, we alternately assigned the volunteering and nonvolunteering identity to the Type A and Type B applications. The volunteering candidate mentioned volunteer activities at a life-saving food provider and/or at a cancer foundation and/or (as an equipment manager) at a sports club.

We alternated between pairs with (non-stereotypical) Flemish-sounding names and pairs with (non-stereotypical) Turkish ${ }^{5}$-sounding names. However, to avoid unequal treatment due to administrative reasons, all the pairs had the Belgian nationality. In addition, we alternated the gender of the pairs. The resulting combinations were sent to the employers in an alternating order, each time with approximately 24 hours in between the pair members.

As a consequence of our experimental design, while the treatment of volunteering was randomly assigned within pairs of applicants, the treatment of a foreign-sounding name was randomly assigned between pairs of applicants. An alternative design would have been to send quartets of applicants to each vacancy with a random assignment of all ethnicity-volunteering combinations. This would have yielded more statistical power at the cost of a (substantially) higher risk of detection of the experiment.

\footnotetext{
${ }^{5}$ The Turkish community forms the most important ethnic minority in Antwerp with a substantial representation at the tertiary education level.
} 
The data for the pairs with a Flemish-sounding name were analysed by Baert and Vujić (2016) with a focus on the general premium of volunteering. We refer to their study for further details on the experimental data gathering.

\section{Results}

The reactions from employers were received by telephone voicemail or email. Table 1 synthesises these call-backs by ethnic origin and volunteer activities. Overall, candidates with a Flemish-sounding name received a positive reaction (i.e. a job interview invitation, a question to provide more information or a proposal of an alternative position) in $19.3 \%$ of their applications. They were immediately invited to a job interview in $9.7 \%$ of the cases. The corresponding percentages for their Turkish counterparts were $15.3 \%$ and $6.4 \%$, respectively. The positive call-back ratio is then calculated by dividing the positive call-back rates of the immigrant subsample by the corresponding positive call-back rates of the native sample. This yields positive call-back ratios of 0.793 and 0.661: immigrant candidates received about $20.7 \%$ fewer positive reactions in a broad sense and 33.9\% fewer job interview invitations. These call-back ratios are significantly different from 1 at the 10\% and 5\% significance level, respectively, and are in line with the evidence for ethnic discrimination in Belgium in 2012 presented by Baert et al. (2015)

\section{TABLE 1 ABOUT HERE.}

When we break down the data according to whether the candidates revealed volunteer activities, we find that the discrimination ratio varies with mentioned volunteering in the expected direction. Non-volunteering migrants received $37.8 \%$ fewer positive call-backs in a broad sense (rate for natives: 0.156; for immigrants: 0.097) and 54.2\% fewer job interview invitations (rate for natives: 0.083; for immigrants: 0.038) than non-volunteering natives. In sharp contrast, the positive call-back ratios are close to (and not statistically significantly different from) 1 when comparing volunteering immigrants with volunteering natives. Therefore, we cannot reject equal treatment of 
natives and immigrants when they both volunteer.

Next, we combine the variation in the two studied outcomes (any positive reaction and a job interview invitation) by means of an ordered logit regression model. The probability of the volunteering applicant receiving a positive call-back was correlated with the probability of the non-volunteering applicant sent to the same vacancy receiving one. Therefore, we present standard errors corrected for clustering at the vacancy level.

Table 2 presents the model estimates as odds ratios. The dependent variable of this model is 2 in the case that the candidate was immediately invited to a job interview, 1 in the case that (s)he received any other positive reaction and 0 in the case that $(\mathrm{s})$ he had no (positive) reaction at all. In model (1), we regress this variable on (i) an indicator of a candidate with a Turkish name, (ii) an indicator of volunteer activities mentioned in the candidate's curriculum vitae, (iii) an interaction between the former two variables (the main variable of interest) and (iv) an indicator of using job application template type B. In line with Table 1, we find that the odds of a better outcome (a job interview invitation versus any other positive reaction; any other positive reaction versus no positive reaction) is $29.4 \%$ lower for candidates with a Turkish name. In addition, and in line with Baert and Vujić (2016), the overall volunteering premium is substantial. More importantly, however, we find that ethnic discrimination is significantly heterogeneous by revealed prosocial engagement of job candidates. The aforementioned odds ratio comparing the positive call-back rates for native and immigrant candidates is $53.2 \%$ higher in cases in which volunteer activities are mentioned. Finally, the coefficient for the variable indicating type $B$ applications shows that the small differences between the application templates did not yield significantly different call-back outcomes for the type $A$ and type $B$ versions.

TABLE 2 ABOUT HERE.

Many countries stimulate immigrant volunteering among the low-educated and among females in particular. Because they are less successful in terms of labour market integration than their high-educated and male counterparts, the marginal benefits (in terms of human and social capital and employers' willingness to hire them) are expected 
to be higher for them (European Commission, 2012; OECD, 2008). Regression model (2) in Table 2 measures whether the relationship between immigrant volunteering and discrimination is indeed heterogeneous by the gender and education level of the job candidates. Therefore, variables indicating high-educated and male candidates are included as such and in interaction with the three independent variables of model (1). However, no statistically significant results are found with respect to the triple interactions between immigrant status, volunteering status and education level or gender. $^{6}$

\section{Conclusion}

In this study, we reported on a field experiment designed to test the relationship between immigrant volunteering and immigrant discrimination. Our results indicated that volunteer activities undertaken by immigrants lower the hiring discrimination that they face and, as a consequence, foster their labour market integration. Hence, our findings are, to some extent, in favour of governments promoting volunteering among immigrants. On the other hand, if volunteering activities by immigrants are promoted on a large scale and are, thereby, scaled up, one could expect that its signalling value might decrease.

\section{References}

Adida, L.A., Laitin, D.A., Valfort, M.-A., 2014. Muslims in France: Identifying a

\footnotetext{
${ }^{6}$ We also analysed whether the relationship between immigrant volunteering and discrimination is heterogeneous by the candidates' total number and particular type of volunteer activities. However, in line with Baert and Vujić (2016), this did not yield significantly heterogeneous treatment effects. Finally, to test the robustness of the presented regression results, we estimated binary logit models for both call-back outcomes separately. The results for these models led to the same empirical conclusions as the ones presented and are available upon request.
} 
discriminatory equilibrium. J. Popul. Econ. 27, 1039-1086.

Arrow, K.J., 1973. The Theory of Discrimination. In: Ashenfelter, O., Rees, A. (Eds.): Discrimination in Labor Markets. Princeton University Press, Princeton.

Baert, S., Cockx, B., Gheyle, N., Vandamme, C., 2015. Is There Less Discrimination in Occupations Where Recruitment Is Difficult? ILR Review 68, 467-500.

Baert, S., De Pauw, A.-S., 2014. Is Ethnic Discrimination due to Distaste or Statistics? Econ. Lett. 125, 270-273.

Baert, S., Vujić, S., 2016. Does it Pay to Care? Prosocial Engagement and Employment Opportunities. IZA Discussion Paper Series 9649.

Becker, G., 1957. The Economics of Discrimination. University of Chicago Press, Chicago.

Bertrand, M., Mullainathan, S., 2004. Are Emily and Greg more employable than Lakisha and Jamal? A field experiment on labor market discrimination. Am. Econ. Rev. 94, 991-1013.

Bisin, A., Patacchini, E., Verdier, T., Zenou, Y., 2011. Ethnic identity and labour market outcomes of immigrants in Europe. Econ. Policy 65, 57-92.

Constant, A.F., Zimmermann, K.F., 2008. Measuring Ethnic Identity and its Impact on Economic Behavior. J. Eur. Econ. Assoc. 6, 424-433.

Derous, E., Nguyen, H.-H., Ryan, A.M., 2009. Hiring Discrimination Against Arab Minorities: Interactions Between Prejudice and Job Characteristics. Hum. Perform. 22, 297-320.

Eriksson, S., Rooth, D.-O., 2014. Do Employers Use Unemployment as a Sorting Criterion When Hiring? Evidence from a Field Experiment. Am. Econ. Rev. 104, 10141039.

European Commission, 2012. EWSI Special Feature 2012/01: Immigrant Volunteering. European Commission, Brussels.

Handy, F., Greenspan, I., 2009. Immigrant Volunteering - A Stepping Stone to Integration. Nonprofit Volunt. Sect. Q. 38, 956-982.

OECD, 2008. Jobs for Immigrants. Labour Market Integration in France, Belgium, the Netherlands and Portugal. OECD, Paris.

Sharma, R., Mitra, A., Stano, M., 2015. Insurance, race/ethnicity, and sex in the 
search for a new physician. Econ. Lett. 137, 150-153. 
Table 1. The Probability of Receiving a Positive Call-Back by Ethnic Origin and Volunteering: Descriptive Analysis.

\begin{tabular}{|c|c|c|c|c|}
\hline & (1) & $(2)$ & (3) & (4) \\
\hline Data selection & $\begin{array}{l}\text { Positive call-back } \\
\text { rate native } \\
\text { subsample }\end{array}$ & $\begin{array}{l}\text { Positive call-back } \\
\text { rate immigrant } \\
\text { subsample }\end{array}$ & $\begin{array}{l}\text { Positive call- } \\
\text { back ratio: } \\
(2) /(1)\end{array}$ & t-value \\
\hline \multicolumn{5}{|c|}{ A. Positive call-back: any positive reaction } \\
\hline All candidates $[\mathrm{N}=1152]$ & 0.193 & 0.153 & $0.793^{*}$ & 1.794 \\
\hline $\begin{array}{l}\text { Candidates not revealing volunteer } \\
\text { activities }[N=576]\end{array}$ & 0.156 & 0.097 & $0.622^{* *}$ & 2.134 \\
\hline $\begin{array}{l}\text { Candidates revealing volunteer } \\
\text { activities }[N=576]\end{array}$ & 0.229 & 0.208 & 0.909 & 0.604 \\
\hline \multicolumn{5}{|c|}{ B. Positive call-back: job interview invitation } \\
\hline All candidates $[\mathrm{N}=1152]$ & 0.097 & 0.064 & $0.661 * *$ & 2.057 \\
\hline $\begin{array}{l}\text { Candidates not revealing volunteer } \\
\text { activities }[N=576]\end{array}$ & 0.083 & 0.038 & $0.458^{* *}$ & 2.274 \\
\hline $\begin{array}{l}\text { Candidates revealing volunteer } \\
\text { activities }[N=576]\end{array}$ & 0.111 & 0.090 & 0.813 & 0.830 \\
\hline
\end{tabular}

The t-test assesses the null hypothesis that the probability of a positive call-back is the same for candidates from both subsamples. $* * *\left(* *{ }^{*}\right)$ indicates significance at the $1 \%(5 \% ; 10 \%)$ significance level. 
Table 2. The Odds of Receiving a Positive Call-Back by Ethnic Origin and Volunteering: Ordered Logit Estimates.

\begin{tabular}{lcc}
\hline \hline & $(1)$ & $(2)$ \\
\hline (a) Immigrant & $0.706^{*}(0.139)$ & $0.772^{*}(0.179)$ \\
(b) Immigrant x Volunteering (normalised) & $1.532^{*}(0.360)$ & $1.635^{*}(0.420)$ \\
(c) Immigrant x Volunteering x High-educated (normalised) & $0.863(0.456)$ \\
(d) Immigrant x Volunteering x Male gender (normalised) & $1.403(0.676)$ \\
(e) Immigrant x High-educated (normalised) & & $0.706(0.322)$ \\
(f) Immigrant x Male gender (normalised) & $1.647(0.680)$ \\
(g) Volunteering (normalised) & $1.587^{* * *}(0.245)$ & $1.552^{* *}(0.271)$ \\
(h) Volunteering x High-educated (normalised) & $0.964(0.352)$ \\
(i) Volunteering x Male gender (normalised) & $1.074(0.121)$ & $1.070(0.128)$ \\
(j) Job application template type B (normalised) & & $4.290^{* * *}(1.329)$ \\
(k) High-educated (normalised) & & $0.411^{* * *}(0.116)$ \\
(l) Male gender (normalised) & 1152 & 1152 \\
\hline Observations & & \\
\hline \hline
\end{tabular}

Variables (b), (e), (f), (g), (j), (k) and (I) are normalised by subtracting their mean among the subpopulation of immigrants. Variables (c), (d), (h) and (i) are normalised by subtracting their mean among the subpopulation of volunteering immigrants. The presented statistics are odds ratios. The dependent variable is $2(1 ; 0)$ in the case that the candidate was immediately invited to a job interview (any other positive reaction; no positive reaction). Standard errors, corrected for clustering at the vacancy level, are between parentheses. ${ }^{* * *}\left({ }^{* *} ;{ }^{*}\right)$ indicates significance at the $1 \%(5 \% ; 10 \%)$ significance level. 